\title{
A comparative study of the reactivity of Brook and Couret silenes: aldehyde addition
}

\author{
Kaarina K. Milnes and Kim M. Baines ${ }^{*}$
}

Department of Chemistry, University of Western Ontario, London, Ontario, Canada, N6A 5B7

\author{
E-mail: kbaines2@uwo.ca
}

* Corresponding Author 


\section{Structure Elucidation}

In the ${ }^{1} \mathrm{H}-{ }^{13} \mathrm{C}$ gHSQC NMR spectrum of vinylsilane 17, two doublet of doublets at 3.67 and 3.55

ppm in the ${ }^{1} \mathrm{H}$ dimension were found to correlate to the same signal at $66.48 \mathrm{ppm}$ in the ${ }^{13} \mathrm{C}$ dimension. By virtue of the chemical shifts and integrations $\left({ }^{1} \mathrm{H}\right.$ only) of these signals, they were assigned to an oxygen-substituted $\mathrm{CH}_{2}$ moiety. A multiplet at 1.35-1.40 ppm in the ${ }^{1} \mathrm{H}$ NMR spectrum of $\mathbf{1 7}$ correlates to the ${ }^{1} \mathrm{H}$ 's of the $\mathrm{OCH}_{2}$ group and to the signals assigned to the other cyclopropyl ${ }^{1} \mathrm{H}$ 's in the $\mathrm{gCOSY}$ NMR spectrum of 17 , and thus, is assigned to $\mathrm{OCH}_{2} \mathrm{CH}_{\text {cycloprop. }}$. A doublet at $6.30 \mathrm{ppm}$ in the ${ }^{1} \mathrm{H} \mathrm{NMR}$ spectrum of 17 was found to correlate to a signal at $6.23 \mathrm{ppm}$ in the gCOSY NMR spectrum of 17; these signals correlated to signals at 158.07 and 122.89 ppm, respectively, in the ${ }^{13} \mathrm{C}$ dimension of the ${ }^{1} \mathrm{H}-{ }^{13} \mathrm{C}$ gHSQC NMR spectrum of $\mathbf{1 7}$. The magnitude of the coupling constant between the ${ }^{1} \mathrm{H}$ signals is 18.6 $\mathrm{Hz}$, and thus, these signals were assigned to the vinylic ${ }^{1} \mathrm{H}$ 's of $\mathbf{1 7}$ and have a trans orientation. The two substituents on the alkene are a $t$-Bu group, as seen by correlations between both vinyl ${ }^{1} \mathrm{H}$ 's to the quaternary ${ }^{13} \mathrm{C}$ of the $t$-Bu substituent in the ${ }^{1} \mathrm{H}-{ }^{13} \mathrm{C}$ gHMBC NMR spectrum of $\mathbf{1 7}$, and a $\mathrm{Mes}_{2} \mathrm{RSi}$ substituent as revealed by correlations between both vinyl ${ }^{1} \mathrm{H}$ 's and the ${ }^{29} \mathrm{Si}$ signal at $-10.4 \mathrm{ppm}$ in the ${ }^{1} \mathrm{H}_{-}{ }^{29} \mathrm{Si}$ gHMBC NMR spectrum of $\mathbf{1 7}$. These data are completely consistent with the assigned structure of 17; no evidence for the formation of the cis-alkene was observed.

The identification of alkenes trans-20 and cis-20 relied heavily on the correlations seen in the gCOSY and ${ }^{1} \mathrm{H}-{ }^{13} \mathrm{C}$ gHMBC NMR spectra. The interpretation of the spectral data for both alkenes was very similar, and thus, only trans-20 will be discussed. A ${ }^{1} \mathrm{H}$ signal at $5.53 \mathrm{ppm}$ (ddt) integrating for $1 \mathrm{H}$ was found to correlate to a signal at $1.89 \mathrm{ppm}$ (dt) integrating for $2 \mathrm{H}$ in the gCOSY NMR spectrum of trans-20. The ${ }^{1} \mathrm{H}$ signal at $1.89 \mathrm{ppm}$ was assigned to $\mathrm{CH}_{2} t-\mathrm{Bu}$. The ${ }^{1} \mathrm{H}$ signal at $5.53 \mathrm{ppm}$ also correlated to a signal at $5.05 \mathrm{ppm}(\mathrm{ddt})$ in the gCOSY spectrum of trans-20, which integrated for $1 \mathrm{H}$. The value of the coupling constant between the signals at 5.53 and $5.05 \mathrm{ppm}$ in the ${ }^{1} \mathrm{H}$ NMR spectrum of trans-20 was $15 \mathrm{~Hz}$. Based on these data, these signals were assigned to a 1,2-trans-disubstituted alkene with a $\mathrm{CH}_{2} t$-Bu substituent. In the gCOSY NMR spectrum of trans-20, the vinyl signal at $5.05 \mathrm{ppm}$ correlated to a signal at $1.60 \mathrm{ppm}$ (tt) which then, in turn, correlated to three more ${ }^{1} \mathrm{H}$ signals. The ${ }^{1} \mathrm{H}$ signal at 1.60 
ppm was assigned to $\mathrm{CH}=\mathrm{CHCH}_{\text {cycloprop }}$ and the other $3{ }^{1} \mathrm{H}$ signals were assigned to the remaining cyclopropyl ${ }^{1} \mathrm{H}$ 's of the phenyl-substituted cyclopropyl ring, the second substituent on the disubstituted alkene. The spectral data of $c i s-\mathbf{2 0}$ were quite similar; however, the coupling constant between the two vinylic ${ }^{1} \mathrm{H}$ 's was found to be $11 \mathrm{~Hz}$, providing evidence for the cis configuration.

In the gCOSY NMR spectrum of ester 19, the observed correlations indicated that there were two different cyclopropyl groups that do not correlate with each other. A signal at $\sim 4.00 \mathrm{ppm}$ in the ${ }^{1} \mathrm{H}$ NMR spectrum of 19 was found to correlate to a ${ }^{1} \mathrm{H}$ on one of the cyclopropyl rings. By virtue of the chemical shift of the signal, it was assigned to an oxy-substituted $\mathrm{CH}_{2}$ group. The ${ }^{1} \mathrm{H}-{ }^{13} \mathrm{C}$ gHMBC NMR spectrum of 19 revealed that both the $\mathrm{OCH}_{2}$ and the ${ }^{1} \mathrm{H}$ 's on the second cyclopropyl ring correlated to a signal at $173.74 \mathrm{ppm}$ in the ${ }^{13} \mathrm{C}$ dimension; the signal at $173.74 \mathrm{ppm}$ was assigned to an ester carbonyl carbon, by virtue of its chemical shift. The presence of the ester moiety was confirmed by IR spectroscopy: an absorption was observed at $1723 \mathrm{~cm}^{-1}$ in the IR spectrum of $\mathbf{1 9}$. These data are consistent with the assigned structure. It was difficult initially to determine that the ester consisted of a mixture of diastereomers and not one compound. In the ${ }^{1} \mathrm{H}$ NMR spectrum of $\mathbf{1 9}$, the chemical shifts of the $\mathrm{OCH}_{2}{ }^{1} \mathrm{H}$ 's are slightly different for the two diastereomers; however, the rest of the chemical shifts and coupling constants in the spectrum are nearly identical. Only a few signals in the ${ }^{13} \mathrm{C}$ NMR spectrum of $\mathbf{1 9}$ for the two diastereomers are non-coincidental. The ${ }^{1} \mathrm{H}$ NMR spectrum of $\mathbf{1 9}$ was also recorded in $\mathrm{CDCl}_{3}$ in an attempt to separate the chemical shifts for the two diastereomers; unfortunately, the chemical shifts were still essentially identical. Furthermore, only one signal was observed by gas chromatography. Given this, it was not possible to determine the ratio of the two diastereomers present.

The cis,trans-dienes $\mathbf{2 3}$ and $\mathbf{2 6}$ and acylsilanes $\mathbf{2 5 a - b}$ were identified by IR, ${ }^{1} \mathrm{H},{ }^{13} \mathrm{C}, \mathrm{gCOSY},{ }^{1} \mathrm{H}$ ${ }^{13} \mathrm{C}$ gHSQC and gHMBC, ${ }^{1} \mathrm{H}_{-}{ }^{29} \mathrm{Si}$ gHMBC NMR spectroscopy and mass spectrometry. In the ${ }^{1} \mathrm{H}$ NMR spectrum of both $\mathbf{2 3}$ and $\mathbf{2 6}$, four signals in the range of 5.25-7.75 ppm, all integrating for $1 \mathrm{H}$, were assigned to the 5-phenyl-1-oxapentadienyl moiety. The 2-cis-4-trans orientation of the diene was assigned based on the chemical shifts and coupling constants of the vinylic ${ }^{1} \mathrm{H}$ signals. 
The mass spectrum of acylsilanes 25a-b revealed a highest mass ion at $\mathrm{m} / \mathrm{z} 479.4$ which confirmed that the compound was a 1:1 adduct between silene 1a and the aldehyde. The downfield signal at $\sim 240 \mathrm{ppm}$ observed in the ${ }^{13} \mathrm{C}$ NMR spectrum of $\mathbf{2 5 a - b}$ was assigned to a carbonyl carbon. The chemical shift of this signal is similar to those previously reported for other acylsilanes. ${ }^{1 \mathrm{~b}}$ An absorption observed at $1615 \mathrm{~cm}^{-1}$ in the IR spectrum of $\mathbf{2 5 a - b}$ was assigned to the $\mathrm{C}=\mathrm{O}$ group of the acylsilane, which is consistent with the $\mathrm{C}=\mathrm{O}$ stretching frequency of known acylsilanes. ${ }^{\mathrm{lb}}$ Based on the observed correlations in the ${ }^{1} \mathrm{H}-{ }^{13} \mathrm{C}$ gHMBC spectrum of acylsilanes 25a-b, it was apparent that the cyclopropyl ring is intact. The sole evidence for acylsilanes $\mathbf{2 8 a}-\mathbf{b}$, derived from the addition of aldehyde $\mathbf{1 0}$ to silene $\mathbf{1 b}$, are the signals at 4.43 and $4.45 \mathrm{ppm}$ in the ${ }^{1} \mathrm{H}$ NMR spectrum of the crude product mixture which are within $0.03 \mathrm{ppm}$ of the chemical shifts of the signals attributable to $\mathrm{Me}_{3} \mathrm{SiOCH}$ in acylsilanes 25a-b derived from silene $\mathbf{1 a}$.

Siloxetanes $\mathbf{2 7} \mathbf{a}-\mathbf{b}$ were identified as components of the crude product mixture by ${ }^{1} \mathrm{H}, \mathrm{gCOSY}$, ${ }^{1} \mathrm{H}^{-29} \mathrm{Si}$ gHMBC NMR spectroscopy. As with siloxetanes 24a-b (from silene 1a), two doublets were observed in the ${ }^{1} \mathrm{H}$ NMR spectrum of the crude reaction mixture at 4.33 and $4.38 \mathrm{ppm} ; J=9.6$ and 9.2 $\mathrm{Hz}$, respectively. The overlap of signals attributable to the adamantyl substituent in the ${ }^{1} \mathrm{H}$ NMR spectrum of the crude reaction mixture obscured the gCOSY NMR spectrum, and thus, it was not possible to identify any signals which could be assigned to the cyclopropyl ${ }^{1} \mathrm{H}$ 's of siloxetanes $\mathbf{2 7 a}$-b with confidence. The ${ }^{1} \mathrm{H}^{29} \mathrm{Si}$ gHMBC NMR spectrum of the crude reaction mixture revealed a correlation between the signals at 4.33 and $4.38 \mathrm{ppm}$ in the ${ }^{1} \mathrm{H}$ dimension and signals at 58.4 and 58.0 ppm, respectively, in the ${ }^{29} \mathrm{Si}$ dimension. These resonances also showed a correlation to two signals between 0.1-0.4 ppm in the ${ }^{1} \mathrm{H}$ dimension which were assigned to two $\mathrm{SiMe}_{3}$ groups, and thus, these signals were assigned to the siloxetane ring ${ }^{29} \mathrm{Si}$ of each diastereomer. The observed ${ }^{29} \mathrm{Si}$ chemical shifts of siloxetanes 27a-b are consistent both with previous reports ${ }^{2}$ and the values reported for siloxetanes 24a-b derived from silene 1a. 
General Experimental Details. All reactions were performed in flame-dried Schlenk tubes or NMR tubes under an inert atmosphere of argon. Irradiations were carried out using three $100 \mathrm{~W}$ mercury spot lamps (Blak-Ray B-100AP series; $\lambda>350 \mathrm{~nm}$ ); the NMR tubes were cooled in a cold water jacket $\left(\sim 6{ }^{\circ} \mathrm{C}\right)$. Benzene- $\mathrm{d}_{6}$ was distilled from LAH prior to use and stored over $4 \AA$ molecular sieves. Pentane was purged with $\mathrm{N}_{2}$ and passed through a column of alumina and a column of copper catalyst prior to use. $t$-BuLi and trans-(2-phenylcyclopropyl)carboxylic acid were purchased from Aldrich Chemical Co.. trans-(2-Phenylcyclopropyl)carboxylic acid was reduced by $\mathrm{LiAlH}_{4}$ in $\mathrm{Et}_{2} \mathrm{O}$ yielding the trans-2-phenylcyclopropane carbinol, ${ }^{3}$ the alcohol was then oxidized under Swern oxidation conditions yielding trans-2-phenylcyclopropane carbaldehyde, $\quad \mathbf{1 0}^{4} \quad$ Pivaloyl and 1 adamantanecarbonyltris(trimethylsilyl)silane, $\quad \mathbf{2 1 a - b},{ }^{1} \quad$ 2-tert-butyl- and 2-(1-adamantyl)-2trimethylsiloxy-1,1-bis(trimethylsilyl)silene, $\mathbf{1 a - b},{ }^{1}$ fluorodimesitylvinylsilane, $\mathbf{1 6},{ }^{5}$ and $1,1-$ dimesityl-2neopentylsilene, $2,{ }^{5}$ were prepared according to the previously reported procedures.

The NMR standards used are as follows: residual $\mathrm{C}_{6} \mathrm{D}_{5} \mathrm{H}(7.15 \mathrm{ppm})$ for ${ }^{1} \mathrm{H}$ NMR spectra and $\mathrm{C}_{6} \mathrm{D}_{6}$ central transition (128.0 ppm) for ${ }^{13} \mathrm{C}$ NMR spectra; $\mathrm{Me}_{4} \mathrm{Si}$ as an external standard, 0 ppm, for ${ }^{1} \mathrm{H}-$ ${ }^{29} \mathrm{Si}$ gHMBC spectra. IR spectra were recorded $\left(\mathrm{cm}^{-1}\right)$ from thin films. Gas chromatographic analyses were performed on a dimethylpolysiloxane column. Mass spectra were obtained using an ionizing voltage of $70 \mathrm{eV}$ and the data are reported in mass-to-charge units, $\mathrm{m} / \mathrm{z}$.

Addition of trans-2-phenylcyclopropane carbaldehyde, 10, to 2-(1-adamantyl)-2trimethylsiloxy-1,1-bis(trimethylsilyl)silene, $\quad$ 1b. $\quad$ A $\quad$ solution $\quad$ of 1 adamantanecarbonyltris(trimethylsilyl)silane, $\mathbf{2 1 b}$, $(110 \mathrm{mg}, 0.27 \mathrm{mmol})$ was irradiated in $\mathrm{C}_{6} \mathrm{D}_{6}(1.0$ $\mathrm{mL}$ ). The progress of the irradiation was monitored by ${ }^{1} \mathrm{H}$ NMR spectroscopy and, after $50 \mathrm{~h}$ of irradiation, the solution consisted of a mixture of silene $\mathbf{1 b}$ and acylsilane $\mathbf{2 1 b}$ in a ratio of 84:16, respectively. A solution of trans-2-phenylcyclopropane carbaldehyde, 10, (38 mg, $0.26 \mathrm{mmol})$ in $\mathrm{C}_{6} \mathrm{D}_{6}$ $(0.5 \mathrm{~mL})$ was added to the yellow solution containing silene $\mathbf{1 b}$ and acylsilane $\mathbf{2 1 \mathbf { b }}$. Upon addition of the aldehyde, the color of the reaction mixture changed to light orange; however, after sitting for $18 \mathrm{~h}$, the 
color of the solution had completely disappeared. The crude reaction mixture consisted of cis,transdiene 26, siloxetanes $\mathbf{2 7 a - b}$, acylsilanes $\mathbf{2 8 a - b}$ in a ratio of 74:12:13:1:1, respectively, as determined by ${ }^{1} \mathrm{H}$ NMR spectroscopy. The solvent was removed by rotary evaporation yielding a pale yellow residue $(138 \mathrm{mg})$. A sample of the crude product mixture $(101 \mathrm{mg}$ ) was separated by preparative thin layer chromatography (silica gel, 1:1/ hexanes: $\mathrm{CH}_{2} \mathrm{Cl}_{2}$ ) yielding the cis,trans-diene $\mathbf{2 6}$ as a colorless oil (35 mg, $0.06 \mathbf{m m o l}$ ). Although siloxetanes $\mathbf{2 7} \mathbf{a}-\mathbf{b}$ and acylsilanes $\mathbf{2 8 a}-\mathbf{b}$ were present in the crude reaction mixture prior to chromatography, these compounds (or decomposition products derived from them) were not isolated from the plate. 


\section{${ }^{1} \mathrm{H}$ NMR spectrum of 17}
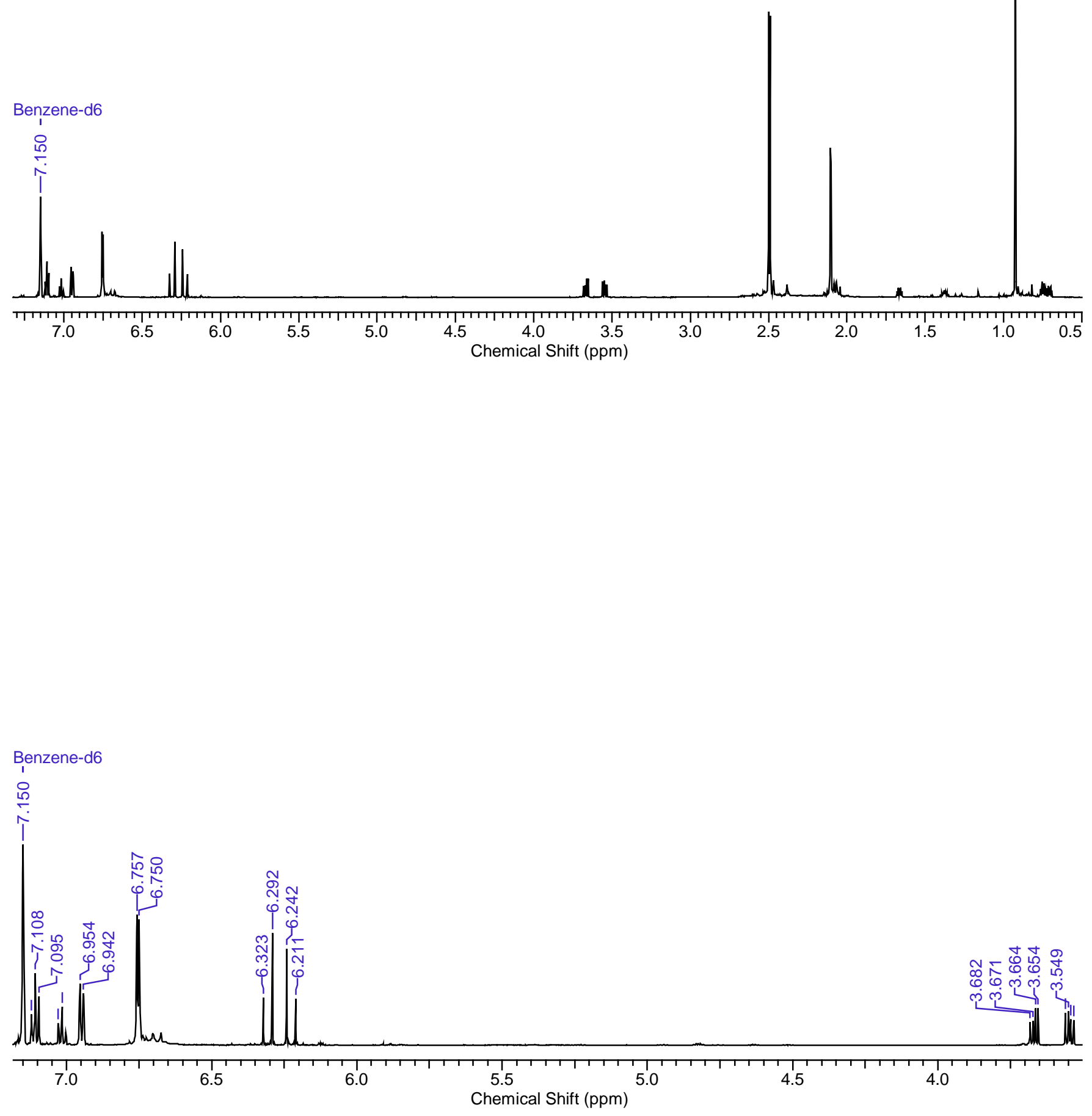


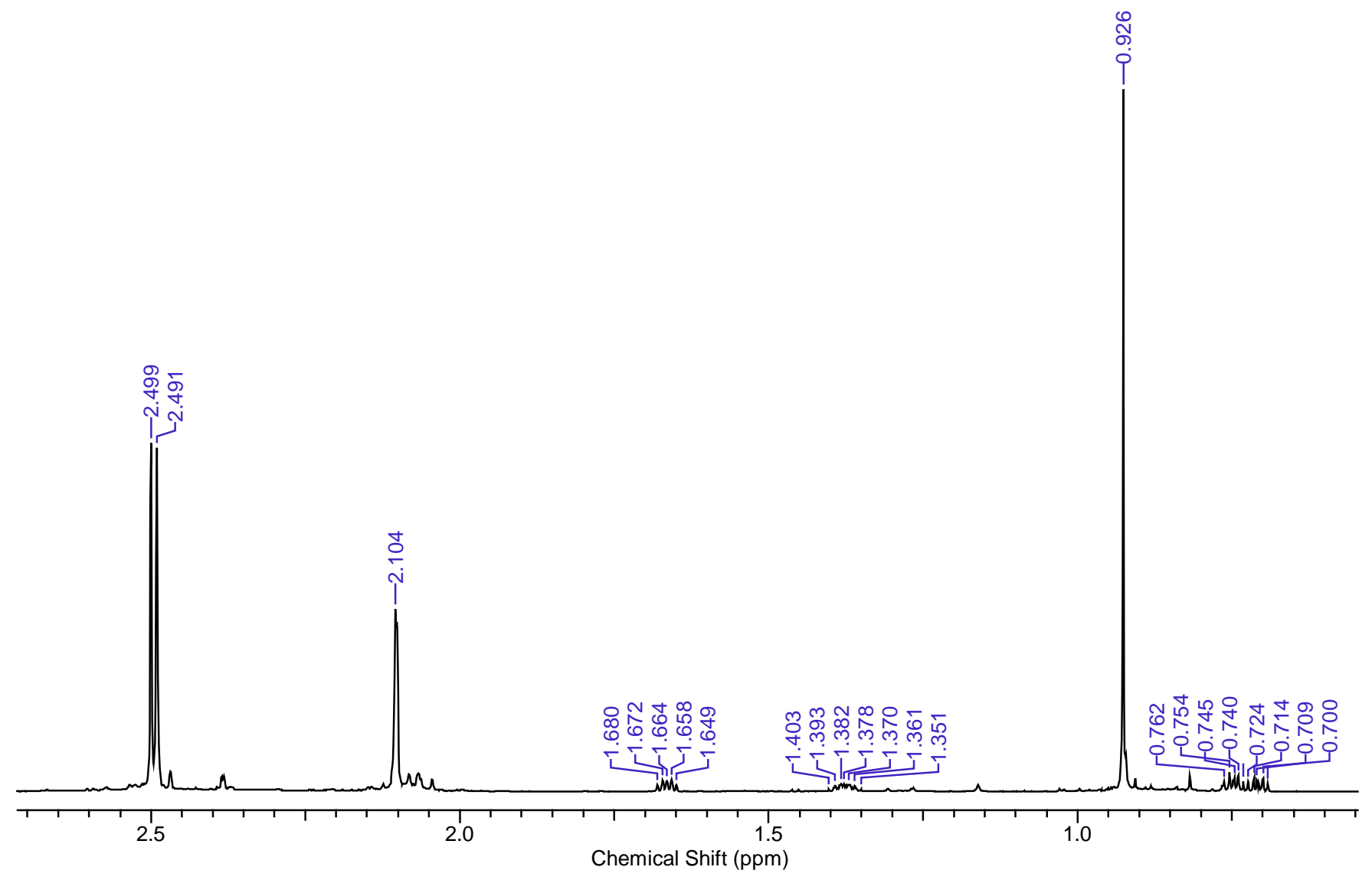

${ }^{13}$ C NMR spectrum of 17

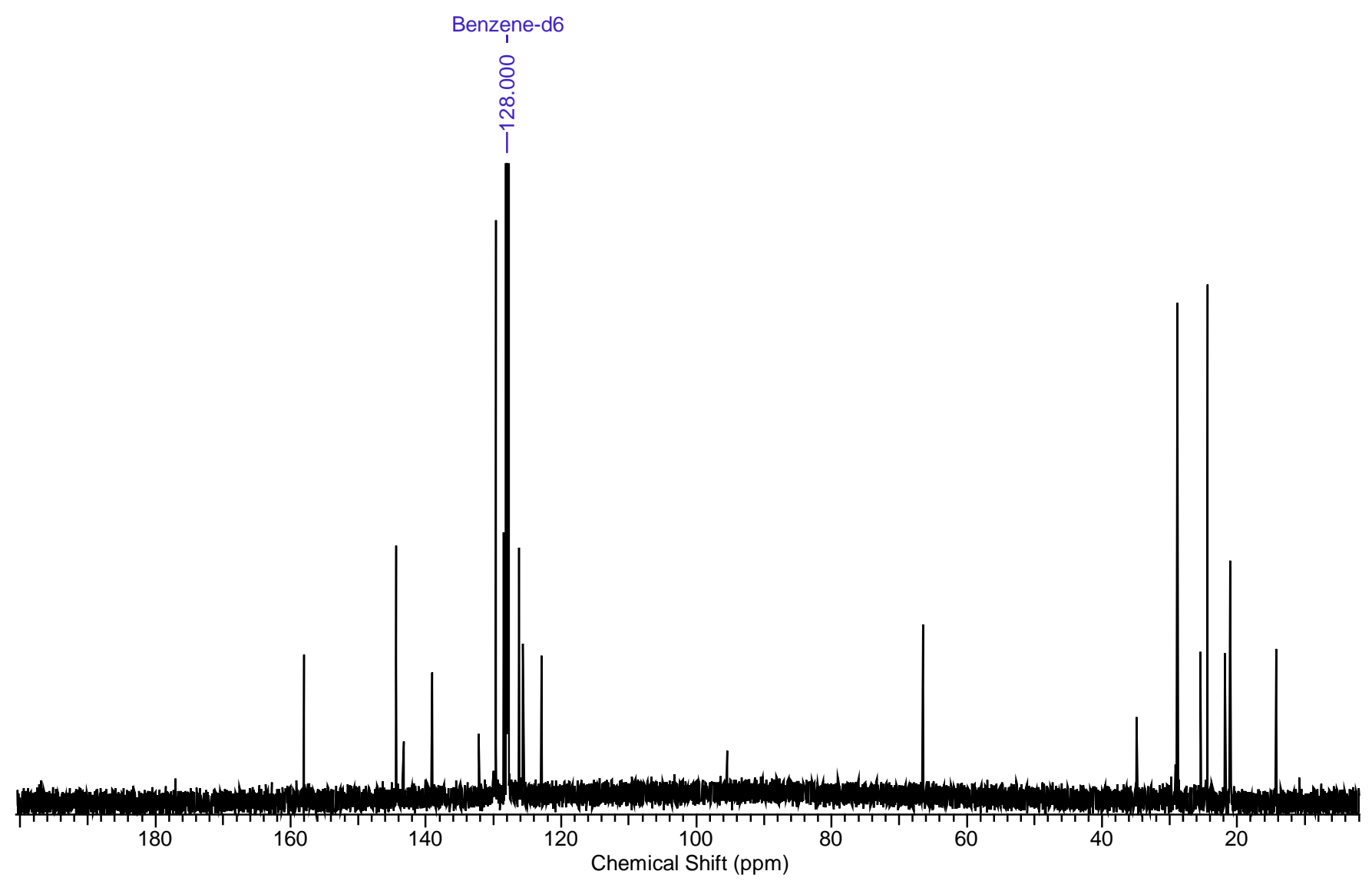




\section{${ }^{1} \mathrm{H}$ NMR spectrum of 19}
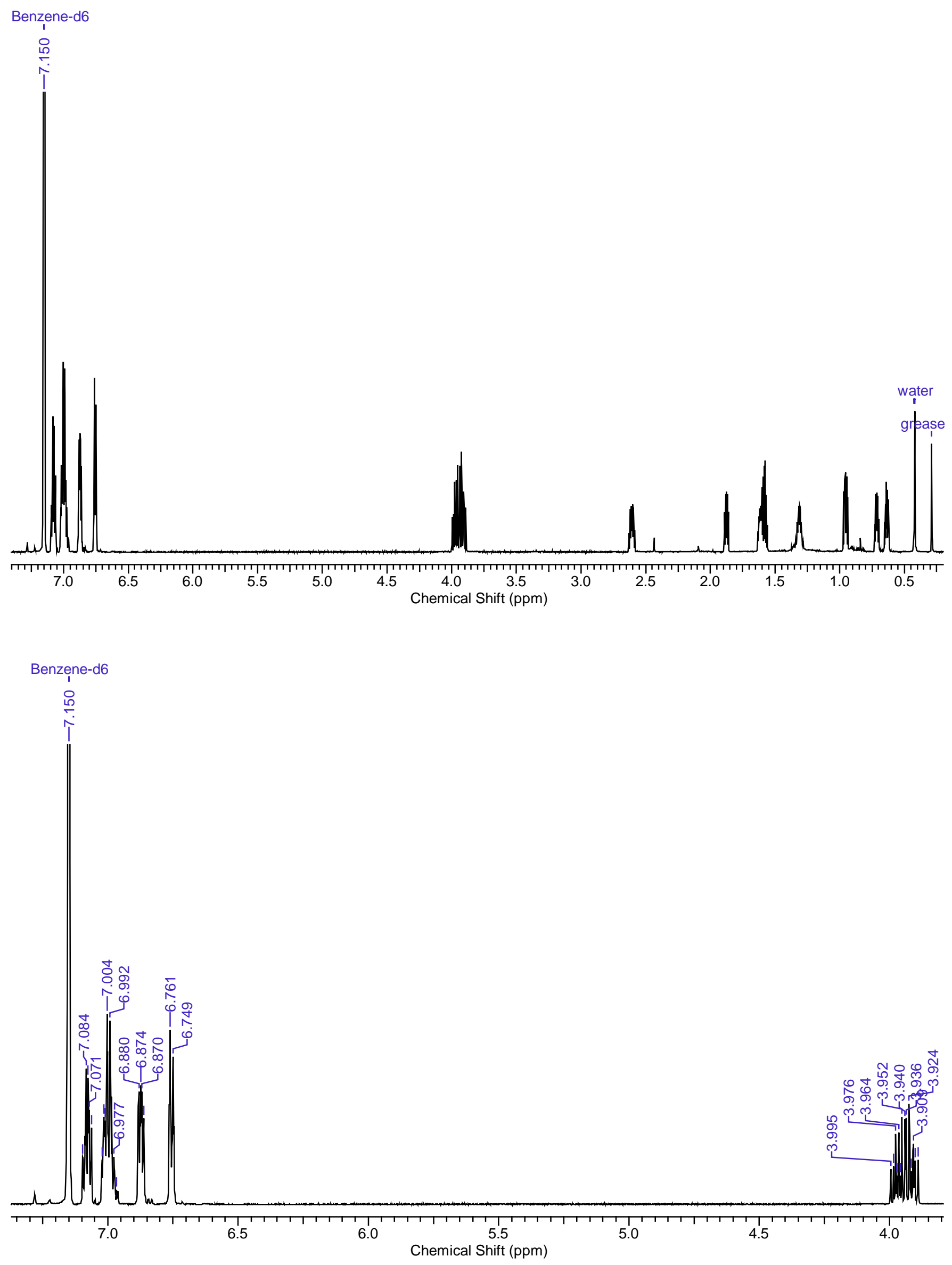


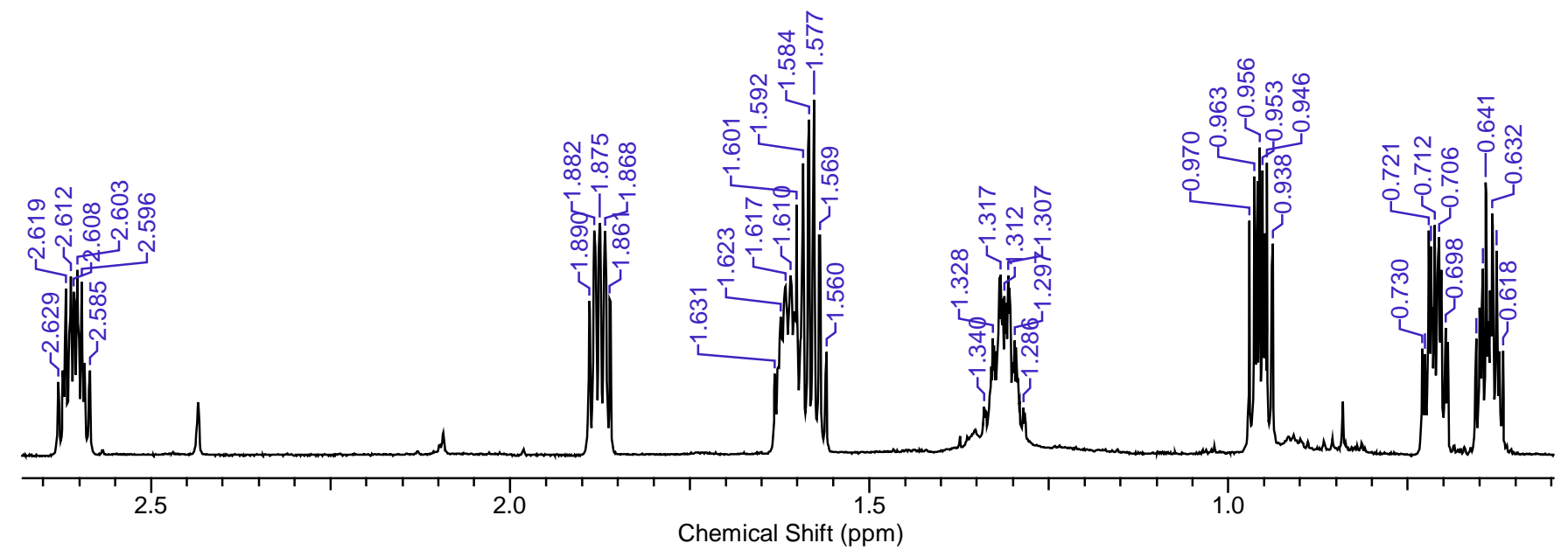

\section{${ }^{13}$ C NMR spectrum of 19}

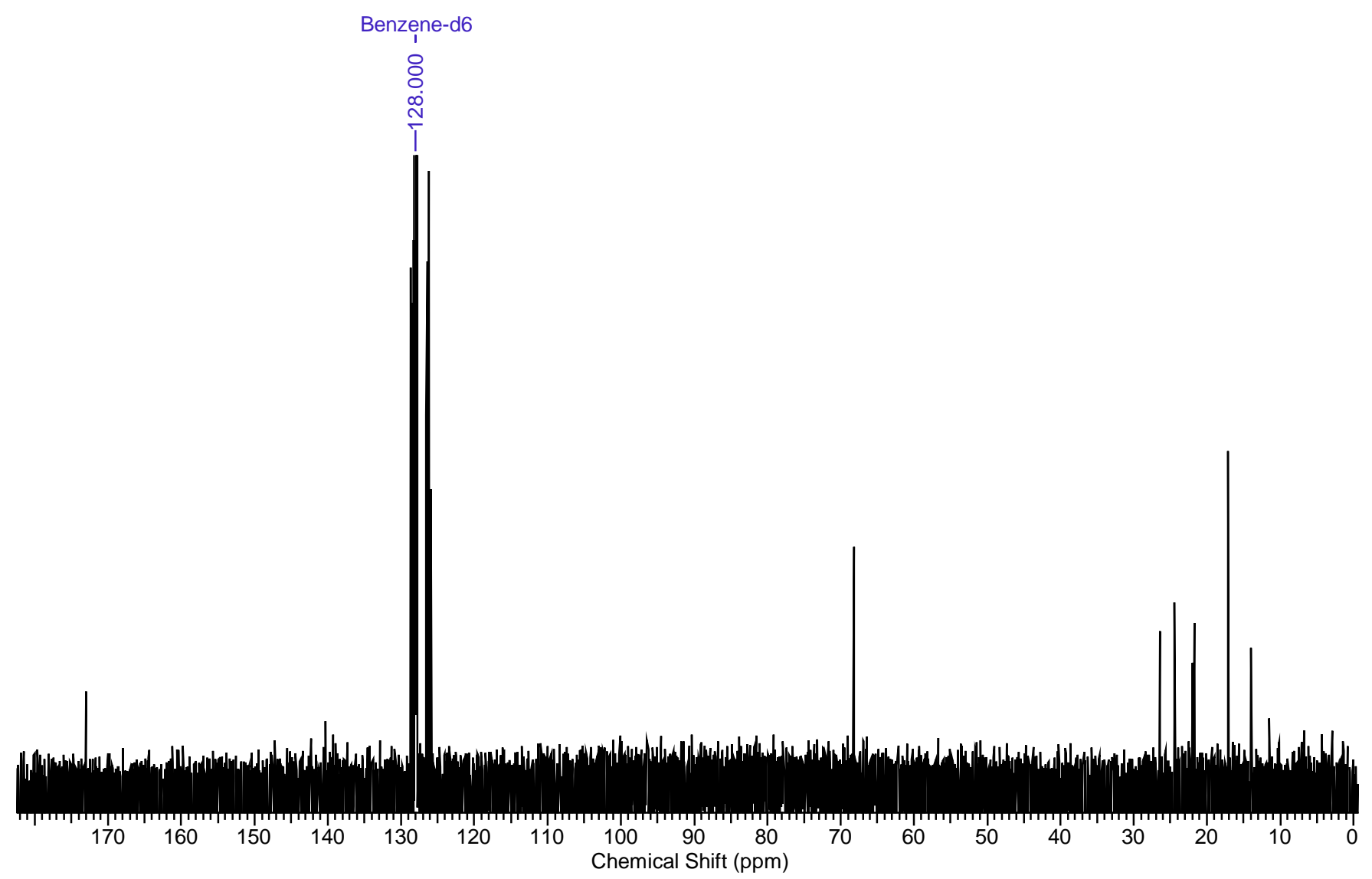




\section{${ }^{1}$ H NMR spectrum of trans- and cis-20}
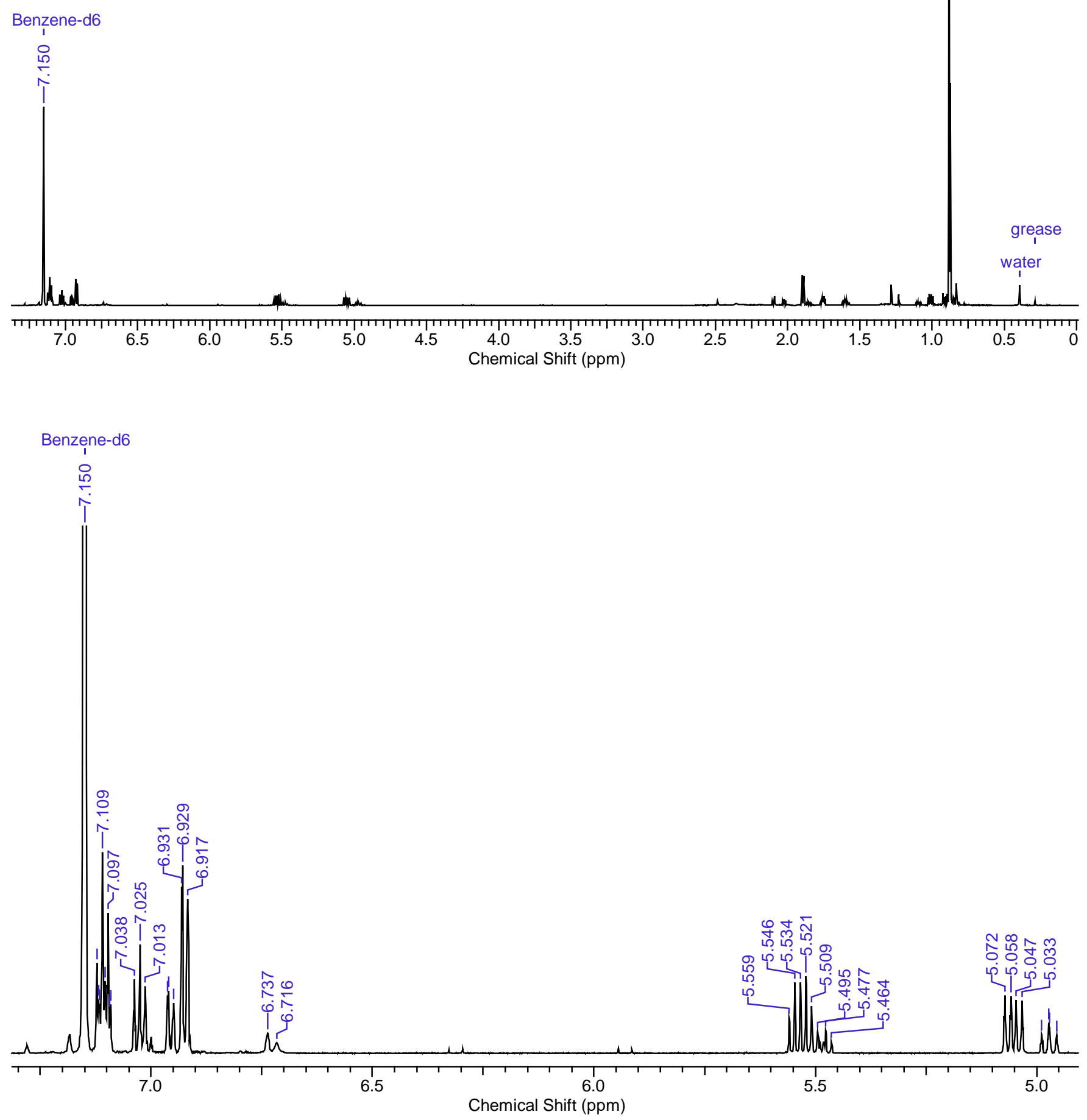


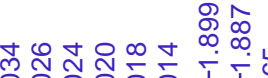

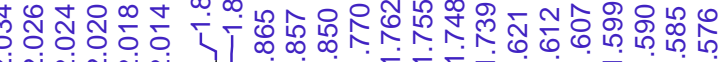

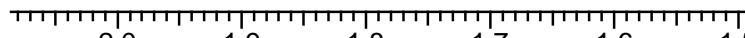

20

1.9

1.8

1.7

1.6

1.5

Chemical Shift (ppm)

\section{${ }^{13} \mathrm{C}$ NMR spectrum of trans- and cis-20}

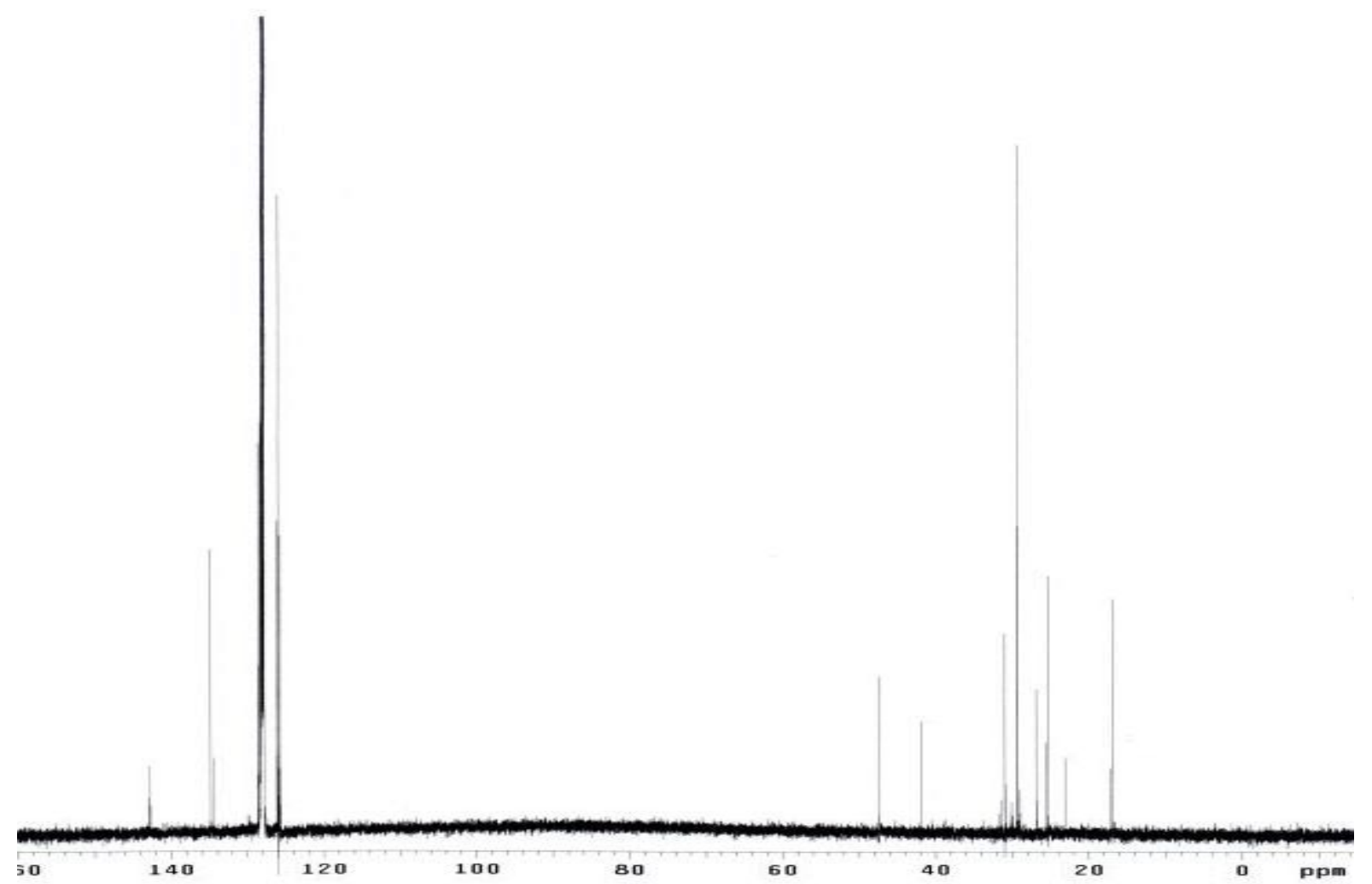


${ }^{1} \mathrm{H}$ NMR spectrum of 23
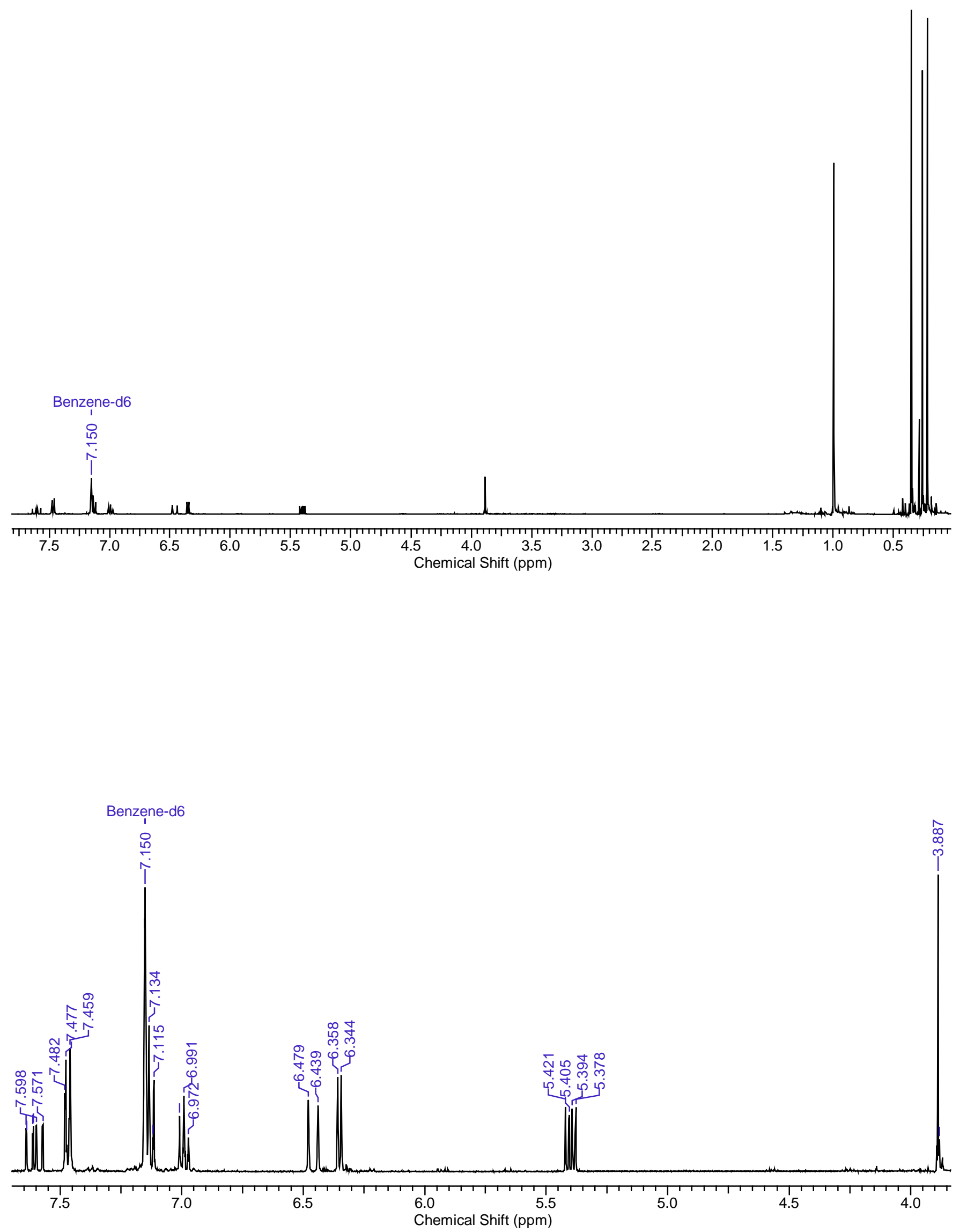


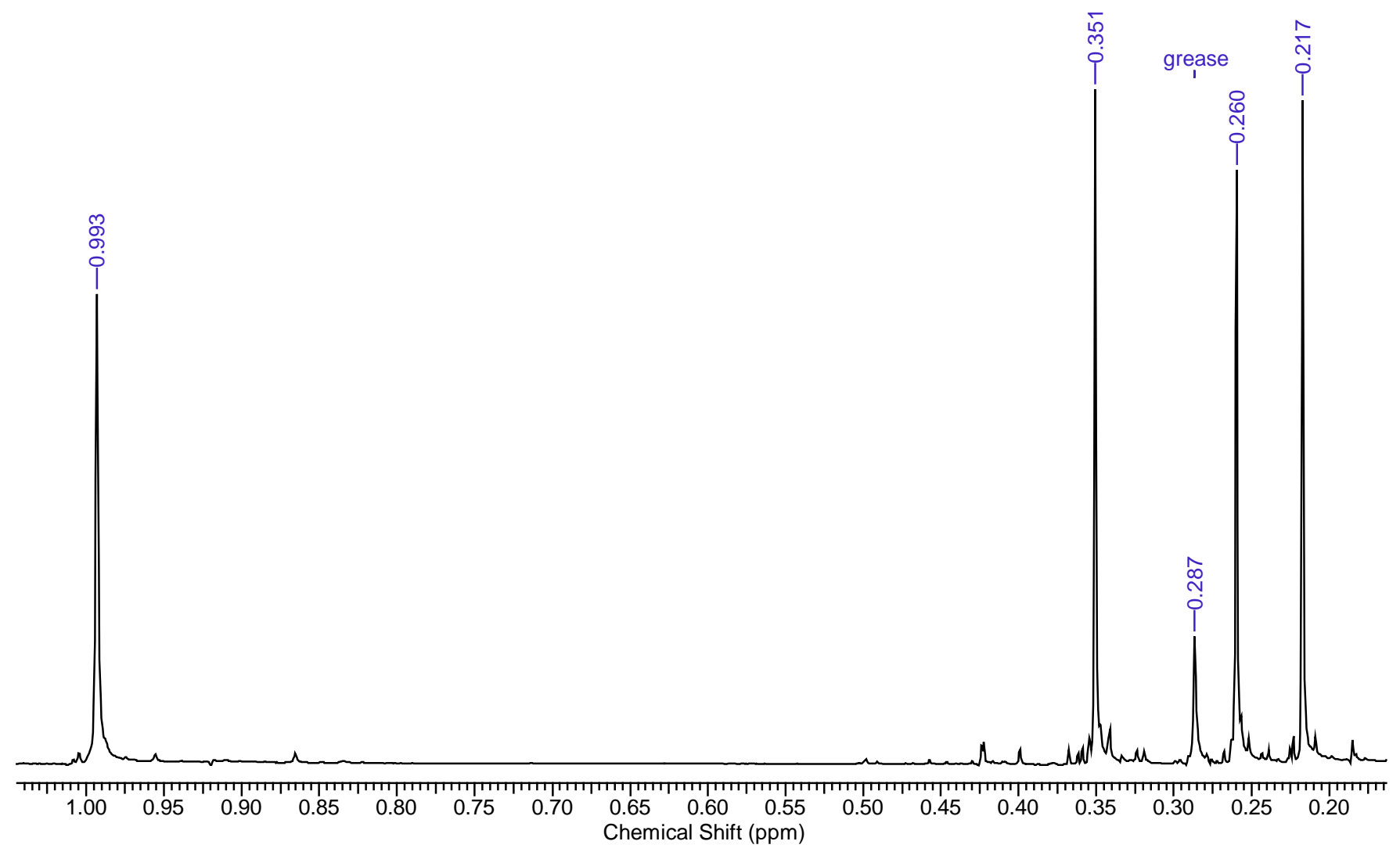

\section{${ }^{13}$ C NMR spectrum of 23}

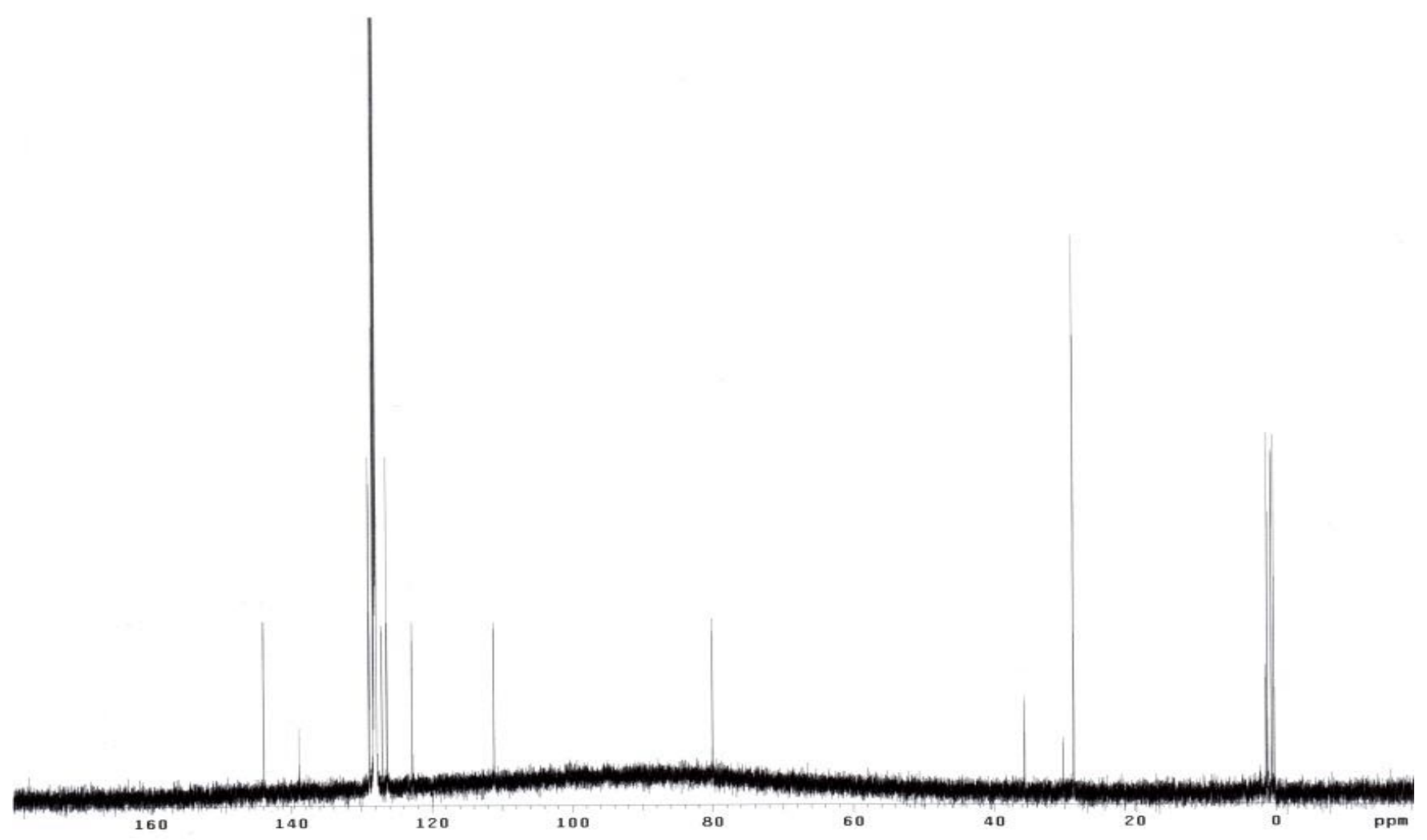




\section{${ }^{1}$ H NMR spectrum of $25 a-b$}
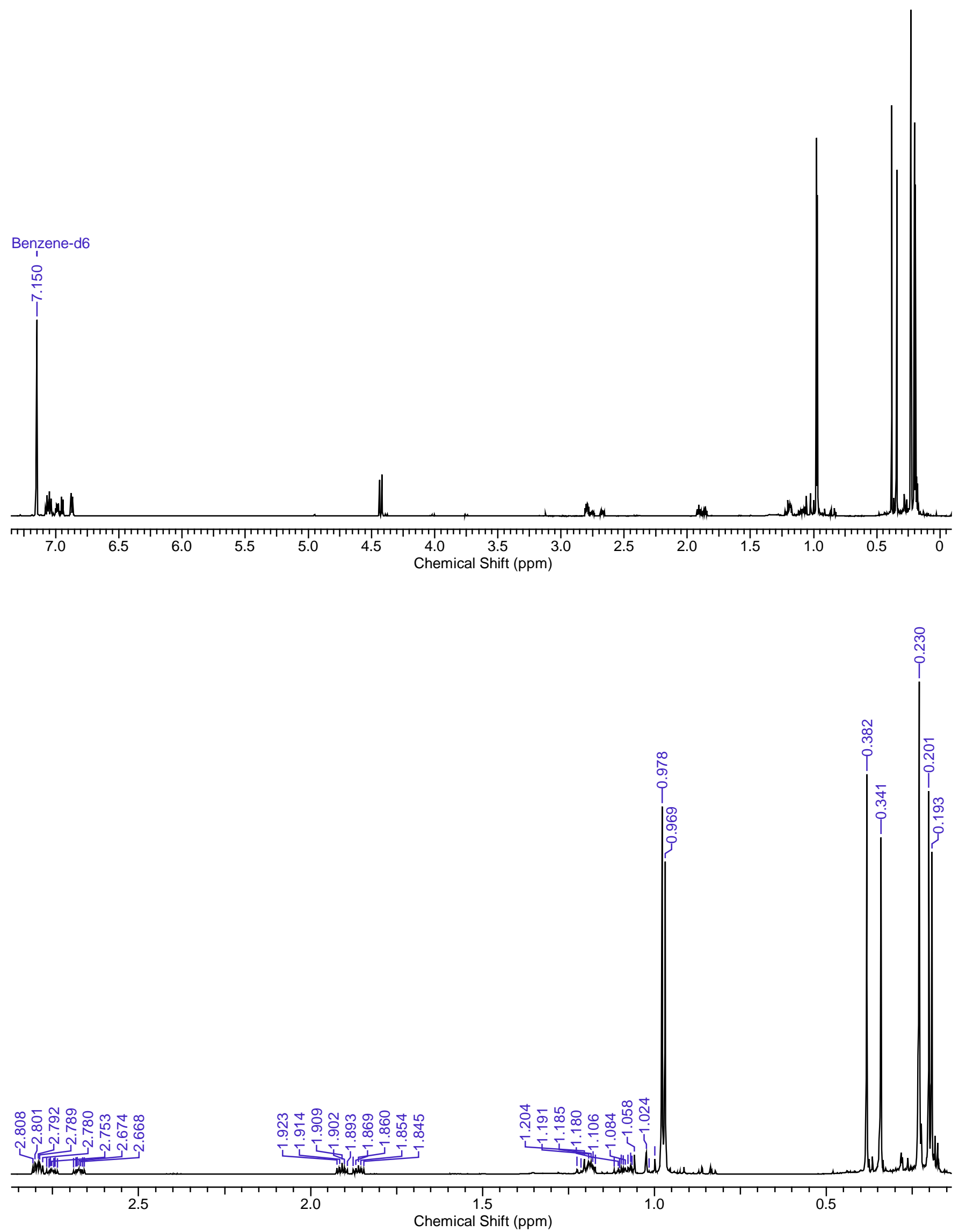


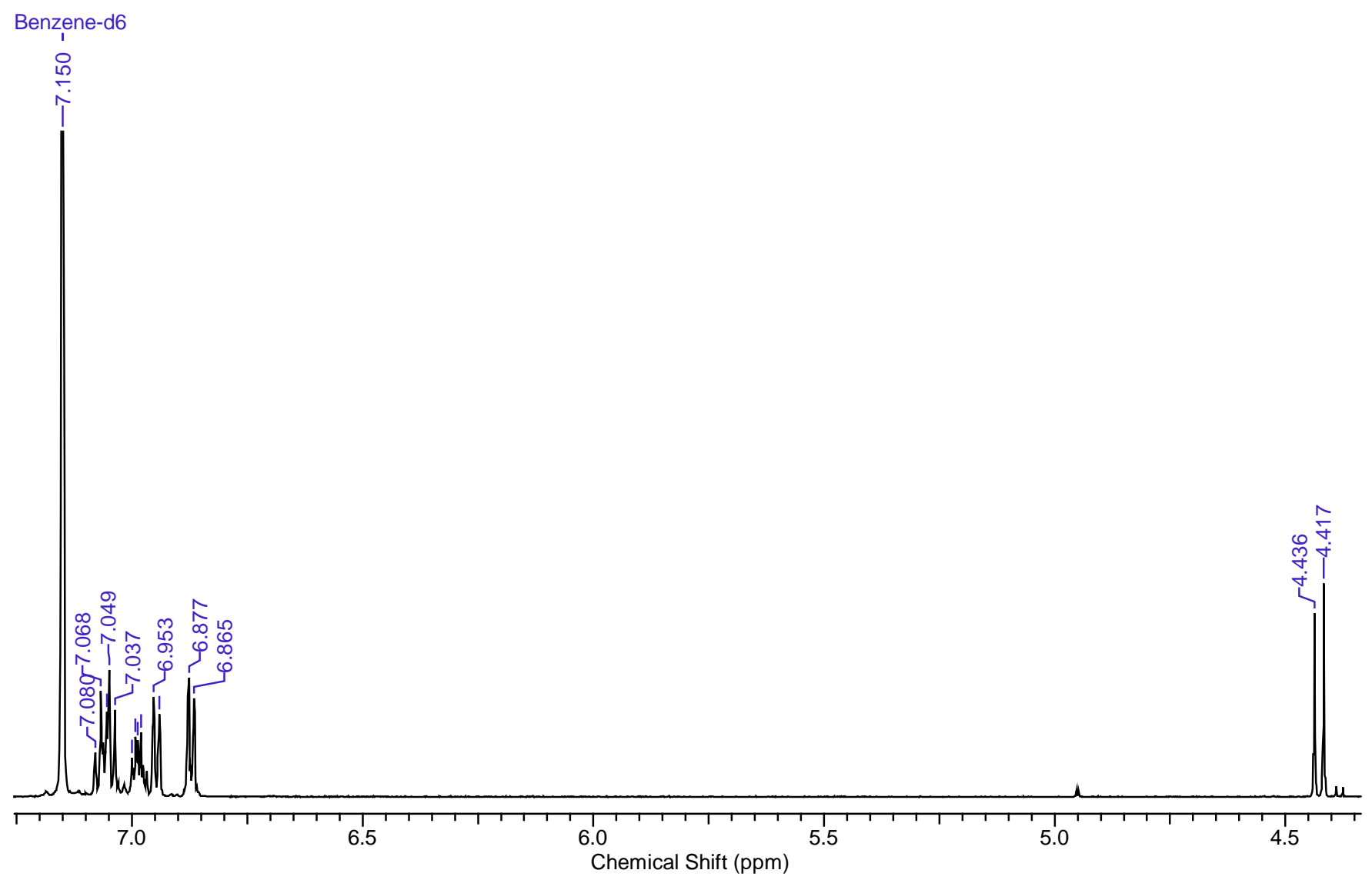

\section{${ }^{13} \mathrm{C}$ NMR spectrum of $25 \mathrm{a}-\mathrm{b}$}

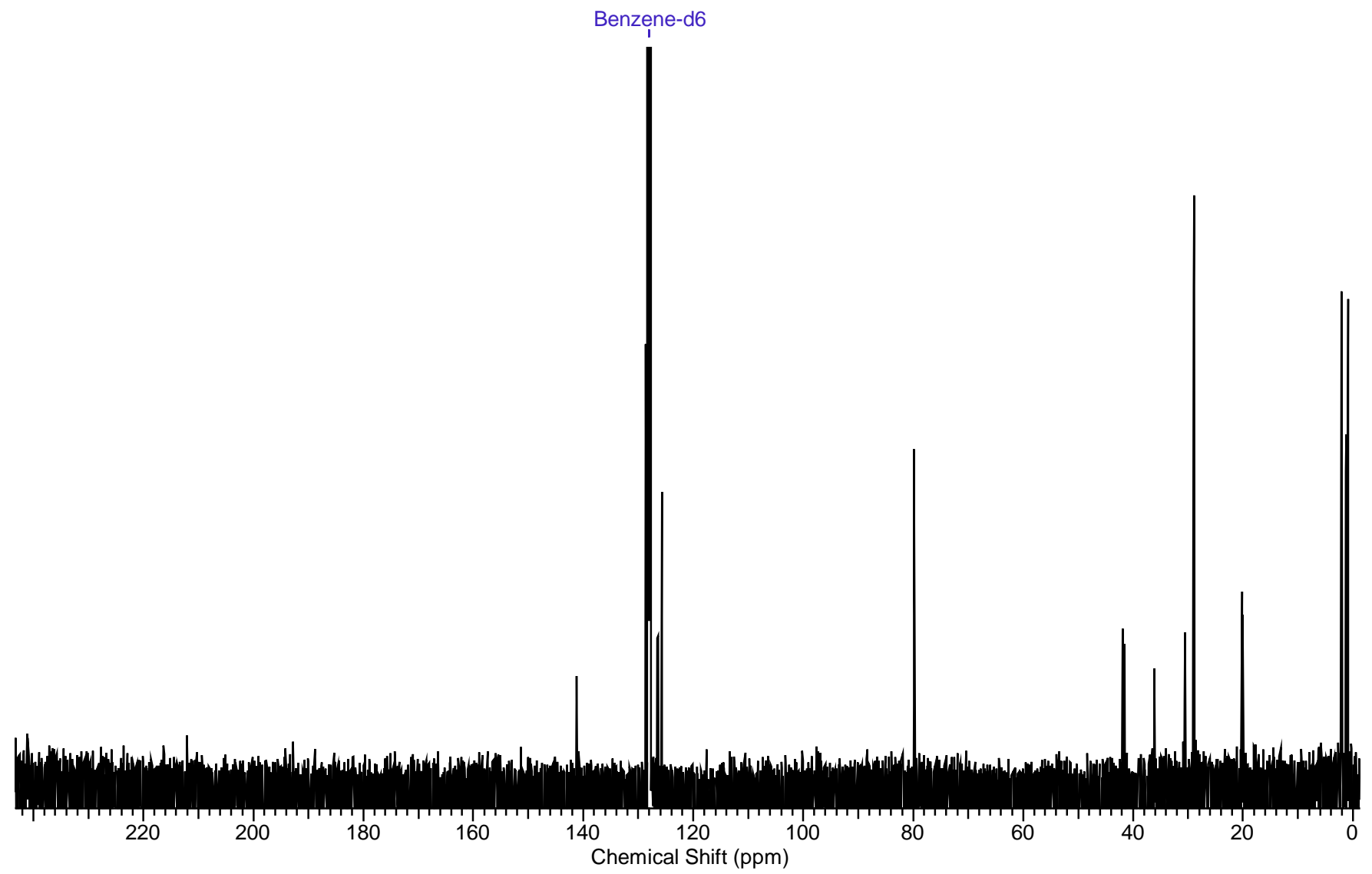




\section{${ }^{1} \mathrm{H}$ NMR spectrum of 26}
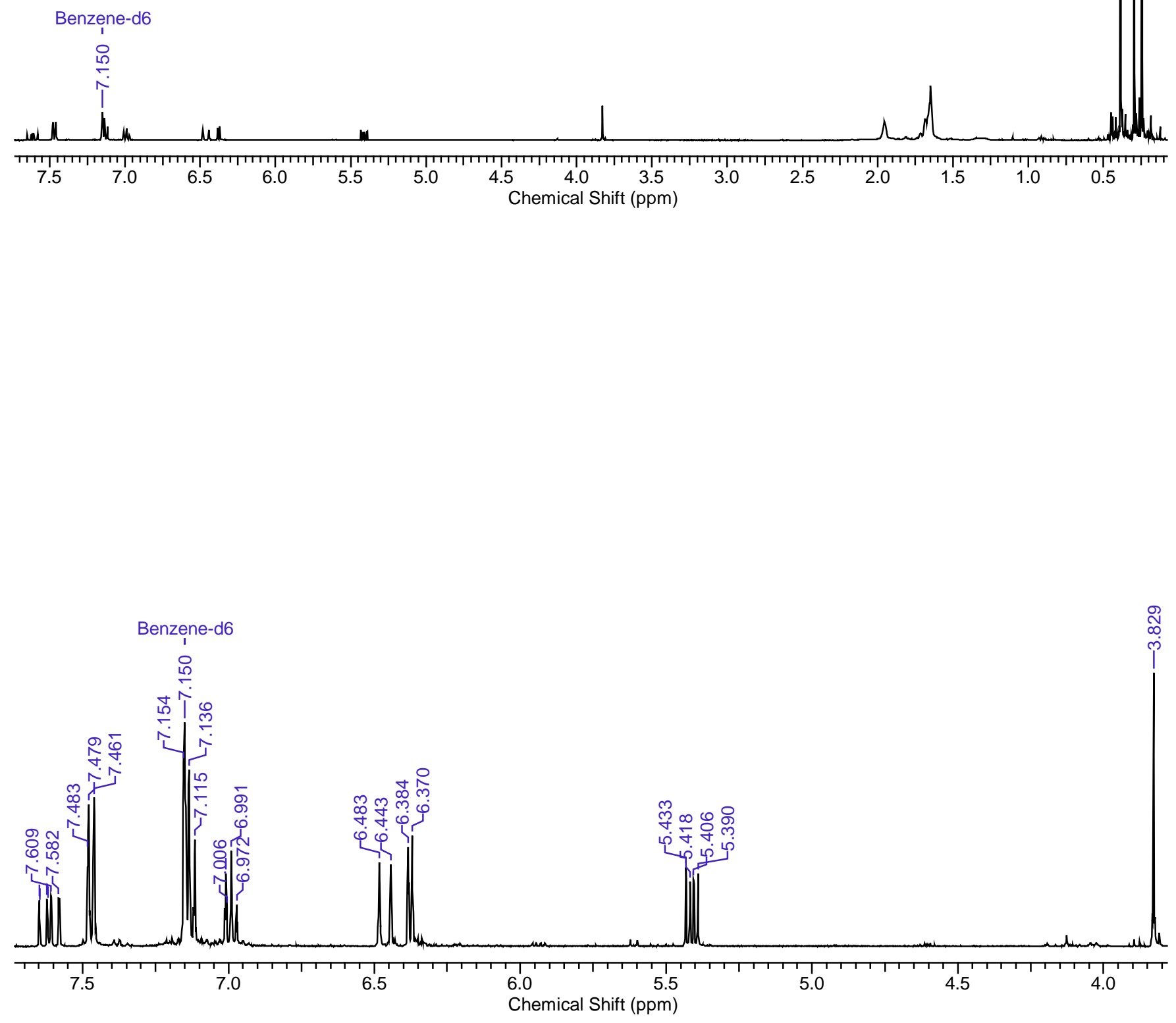


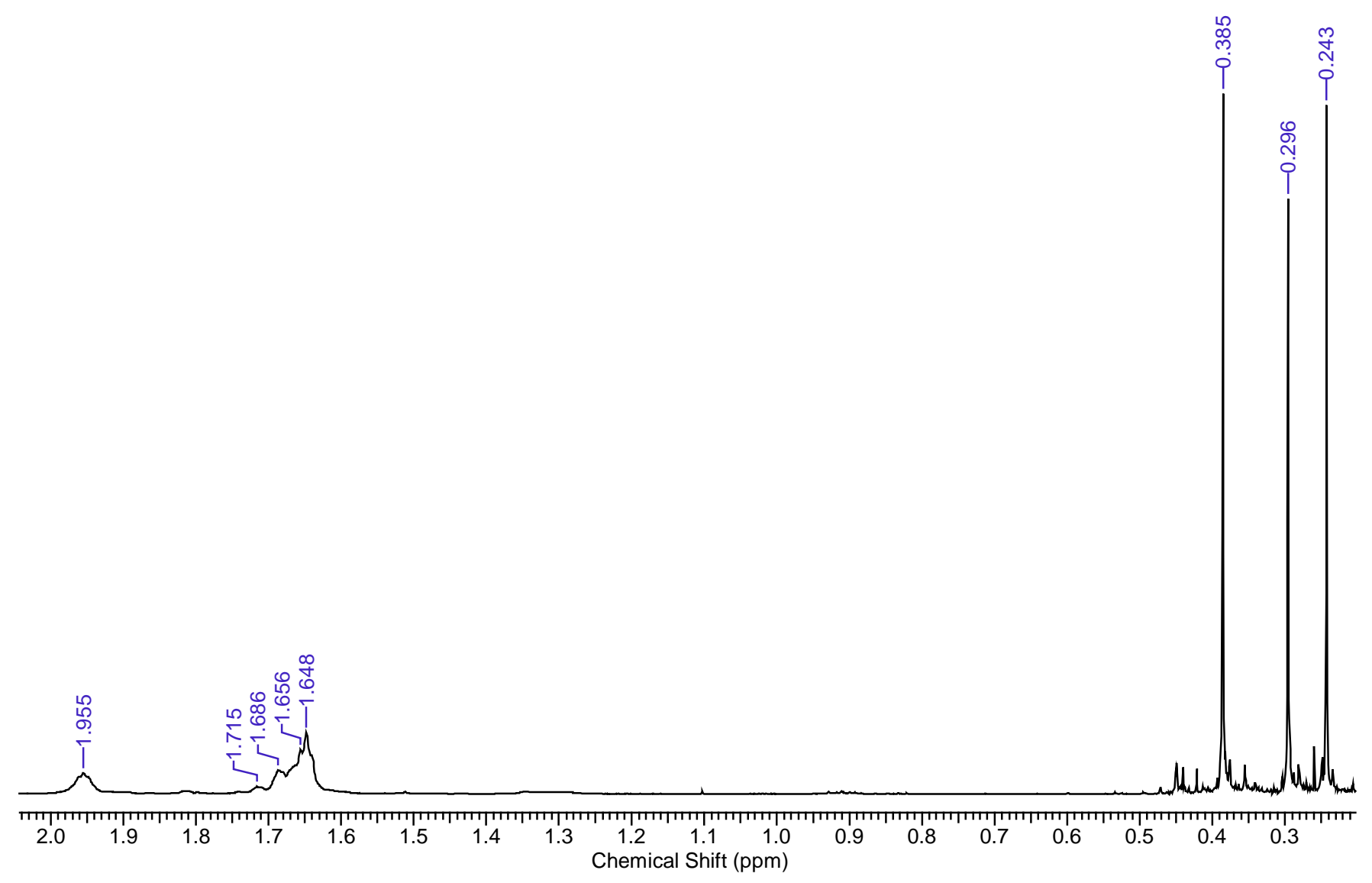

${ }^{13} \mathrm{C}$ NMR spectrum of 26

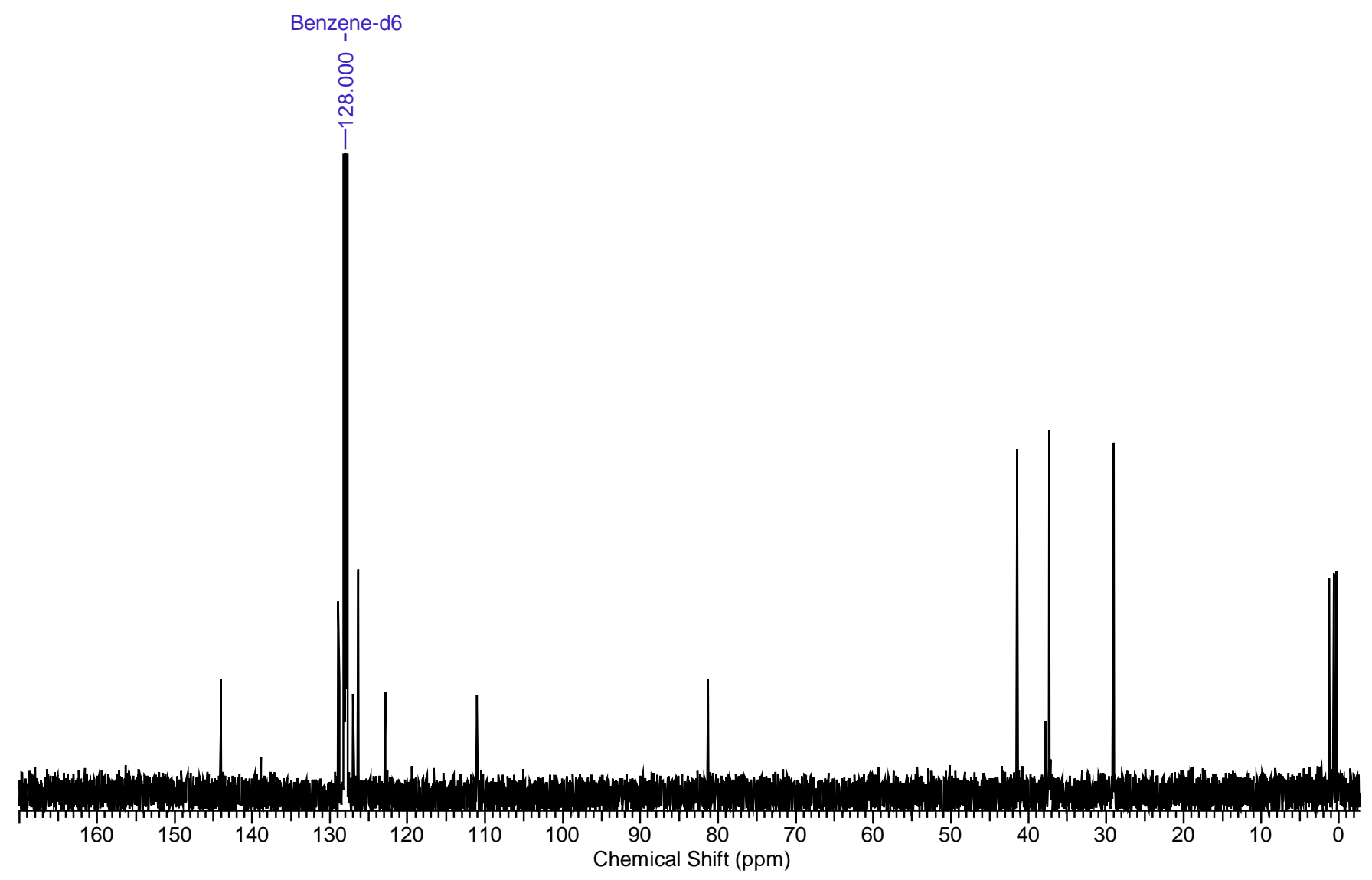




\section{References}

(1) (a) Brook. A. G.; Harris, J. W.; Lennon, J.; El Sheikh, M. J. Am. Chem. Soc. 1979, 101, 83. (b)

Brook, A. G.; Nyburg, S. C.; Abdesaken, F.; Gutekunst, B.; Gutekunst, G.; Kallury, R. K. M. R.; Poon, Y. C.; Chang, Y.-M.; Wong-Ng, W. J. Am. Chem. Soc. 1982, 104, 5667.

(2) Brook, A. G.; Chatterton, W. J.; Hughes, D. W.; Vorspohl, K. Organometallics 1987, 6, 1246.

(3) Smart, R. P.; Peelen, T. J.; Blankespoor, R. L.; Ward, D. L. J. Am. Chem. Soc. 1997, 119, 461.

(4) Abdallah, H.; Grée, R.; Carrié, R. Bull. Soc. Chim. Fr. 1985, 5, 794.

(5) (a) Delpon-Lacaze, G.; Couret, C. J. Organomet. Chem. 1994, 480, C14. (b) Delpon-Lacaze, G.; de Battisti, C.; Couret, C. J. Organomet. Chem. 1996, 514, 59. 